\title{
Inserção de um grupo virtual na rede social de apoio ao aleitamento materno exclusivo de mulheres após a alta hospitalar
}

\author{
Inclusion of a virtual group in a social support network to exclusive \\ breastfeeding after hospital discharge (abstract: p. 17)
}

Inserción de un grupo virtual en la red social de apoyo a la lactancia materna exclusiva de mujeres después de recibir el alta del hospital (resumen: p. 17)

\author{
Caroline Sousa Cabral(a) \\ $<$ carolinescabral@gmail.com> \\ Débora Silva Cavalcanti ${ }^{(b)}$ \\ <deborasec@gmail.com> \\ Janine Maciel Barbosa(c) \\ <janinebarbosa@gmail.com>
}

Ana Cláudia Cavalcanti Peixoto de Vasconcelos ${ }^{(\mathrm{d})}$

<anacpeixoto@uol.com.br>

\author{
(a) Programa de Pós-Graduação \\ em Ciências da Nutrição, \\ Universidade Federal da \\ Paraíba (UFPB). Campus \\ I, Loteamento Cidade \\ Universitária, $\mathrm{s} / \mathrm{n}$. João \\ Pessoa, PB, Brasil. \\ 58051-900. \\ $(b, c)$ Unidade de Nutrição \\ Clínica, Hospital Universitário \\ Lauro Wanderley. João \\ Pessoa, PB, Brasil. \\ (d,e) Departamento de Nutrição, \\ UFPB. João Pessoa, PB, Brasil.
}

Rodrigo Pinheiro de Toledo Vianna(e)

<rodrigopissoa@gmail.com> (iD

\begin{abstract}
Apesar dos benefícios do aleitamento materno exclusivo para a saúde materno-infantil, sua interrupção precoce ainda é muito frequente. O período após a alta hospitalar é o momento em que a mulher se depara com a maioria das dificuldades, sendo importante fortalecer as ações de apoio à amamentação. Este trabalho teve por objetivo desvelar as contribuições da inserção de uma comunidade virtual na rede social de apoio ao aleitamento materno exclusivo de mulheres após a alta hospitalar. Trata-se de um estudo qualitativo, realizado em um grupo privado da rede social Facebook, gerenciado por profissionais de saúde, utilizando-se como referencial metodológico a Pesquisa Participativa Baseada na Comunidade. 0 grupo foi um instrumento de promoção de diálogo e interação entre mulheres a partir de experiências contextualizadas com a realidade, propiciando a construção de novas relações interpessoais e ampliando suas redes sociais de apoio.
\end{abstract}

Palavras-chave: Aleitamento materno exclusivo. Apoio ao aleitamento materno. Mídia social. Apoio social. Pesquisa Participativa Baseada na Comunidade.

Cabral CS, Cavalcanti DS, Barbosa JM, Vasconcelos ACCP, Vianna RPT. Inserção de um grupo virtual na rede social de apoio ao aleitamento materno exclusivo de mulheres após a alta hospitalar. Interface (Botucatu). 2020; 24: e190688 https://doi.org/10.1590/Interface.190688 


\section{Introdução}

Os benefícios do aleitamento materno para a saúde materno-infantil são amplamente reconhecidos na literatura, contribuindo de forma significativa na redução da taxa de mortalidade infantil ${ }^{1-3}$. Do ponto de vista psicossocial, essa prática também é essencial para o fortalecimento do vínculo entre a mãe e o filho . A Organização Mundial de Saúde (OMS) recomenda o aleitamento materno exclusivo (AME) até os seis primeiros meses da criança, complementado até o segundo ano de vida ou mais 5 .

Apesar dessas potencialidades, a interrupção precoce do AME ainda ocorre com muita frequência. No Brasil, uma pesquisa nacional realizada em 2008 evidenciou prevalência de $41 \%$ entre crianças menores de seis meses ${ }^{6}$. Dados mais recentes dos Estados Unidos mostraram que essa prevalência é em torno dos $18 \%{ }^{7}$.

Além das estratégias de promoção e proteção ao aleitamento materno, o início e o estabelecimento do AME depende de práticas apoiadoras. O Brasil conta com uma exemplar articulação de diferentes atores sociais que favorecem a amamentação, porém, é importante valorizar as estratégias locais ${ }^{8}$. Práticas de educação em saúde direcionadas ao apoio ao AME após a alta hospitalar necessitam ser fortalecidas, visto que é nessa ocasião que a mulher se depara com as principais dificuldades, anseios e inquietudes relacionadas ao aleitamento?

As redes sociais on-line têm sido bastante utilizadas por usuários de todo o mundo, facilitando a troca de experiências e conhecimentos, constituindo-se em um cenário atrativo à interação entre usuários e favorecendo a aprendizagem colaborativa ${ }^{10}$. As mídias digitais têm representado um lócus estratégico de apoio ao AME no período pós-parto ${ }^{11}$.

Este trabalho objetivou desvelar as contribuiçôes da inserção de uma comunidade virtual na rede social de apoio ao AME de mulheres após a alta hospitalar, em uma capital da região Nordeste do Brasil.

\section{Metodologia}

\section{Cenário da pesquisa}

Este trabalho foi realizado com mulheres que integraram um grupo privado da rede social Facebook, intitulado Projeto Amamenta Mamãe. O objetivo desse projeto foi promover e apoiar o AME após a alta hospitalar. Essa iniciativa esteve vinculada ao Departamento de Nutrição e ao Hospital Universitário Lauro Wanderley (HULW), ambos da Universidade Federal da Paraíba (UFPB). A equipe moderadora foi composta por profissionais do HULW, professores da Universidade Federal de Pernambuco e da UFPB, além de estudantes dos diferentes cursos da área da saúde de faculdades públicas e privadas do município de João Pessoa. 
O presente estudo se constitui em um recorte da amostra do ensaio clínico randomizado intitulado "Efeitos de uma intervenção para promoção e apoio ao aleitamento materno por meio de rede social on-line”, cuja intervenção foi o Projeto Amamenta Mamãe, cenário de pesquisa deste trabalho. Foram elegíveis para participar do presente estudo as mulheres inseridas nesse grupo, cujos filhos eram menores de seis meses de idade, totalizando 143 integrantes.

O acompanhamento e as práticas do projeto ocorreram conforme os pressupostos de uma Pesquisa Participativa Baseada na Comunidade - Community-Based Participatory Research (CBPR $)^{12,13}$. Nesse grupo, a participação era estimulada pela inserção semanal de cartazes ilustrativos, elaborados pela equipe moderadora, relacionados a importantes experiências das mulheres durante a fase inicial de amamentação, totalizando 24 temas. Esses foram construídos a partir das recomendaçóes do Ministério da Saúde do Brasil, endossadas pela OMS. As usuárias eram marcadas nessas publicaçôes para estimular sua interação na rede virtual, fortalecendo o compartilhamento das experiências; valorizando a troca de saberes e aprendizados da vida cotidiana; e promovendo novos temas para serem abordados.

Considerando-se que a CBPR propóe que a condução do processo se dê por todos os parceiros que integram a pesquisa, os comentários das participantes sobre as publicações e nos tópicos convidativos à interação fomentaram as discussóes subsequentes no feed de notícias. A partir da inserção dessa metodologia participativa, o grupo constituiu-se em um espaço de discussão e compartilhamento de vivências, dificuldades e anseios entre mulheres que vivenciavam o processo de amamentação.

\section{Caracterização do estudo e construção dos dados}

Trata-se de um estudo qualitativo, que analisa a experiência vivenciada por mulheres durante o processo de aleitamento, conforme os pressupostos da $\mathrm{CBPR}^{12,13}$. A coleta dos dados foi realizada por meio de entrevistas conduzidas pela própria autora - que foi uma das coordenadoras do Projeto Amamenta Mamãe - realizada nos domicílios das participantes.

A seleção das mulheres para a coleta ocorreu de modo intencional, entre usuárias que participavam ativamente do grupo do Facebook. Para tanto, selecionaram-se aquelas com maior número de comentários no grupo. Caso esse quantitativo fosse semelhante, procedia-se à contagem de reaçôes expressadas (demonstrações de sentimento, curtidas e desaprovações). Se esse critério não fosse suficiente para a seleção, contabilizava-se o número de visualizaçóes. Optou-se por selecionar as usuárias mais participativas, pois o objetivo das entrevistas foi aprofundar o entendimento do apoio ofertado pelo Facebook.

Do total de vinte convites feitos, 15 mulheres aceitaram participar desse momento da pesquisa. Das 15 entrevistas realizadas, quatro foram desconsideradas em virtude da presença de membros da família durante a gravação. Optou-se por excluir esses sujeitos, considerando que a análise de suas falas poderia acarretar vieses importantes, trazendo outras percepçôes, diferentes das experimentadas pelas participantes. Portanto, este trabalho traz a análise dos depoimentos de 11 mulheres que participaram do projeto. 
Utilizando a técnica de saturação das informações, esse quantitativo de entrevistas foi suficiente para garantir o poder de informação necessário à análise, não sendo necessárias novas coletas, considerando que novos achados não acrescentariam contribuições significativas ${ }^{14}$.

\section{Procedimento de coleta e análise de dados}

As entrevistas ocorreram entre os meses de abril e junho de 2017. O tempo de duração variou entre 32 e 88 minutos e a condução das falas ocorreu com apoio de um roteiro, que incluiu uma identificação inicial e das seguintes questôes norteadoras: a) O que a amamentação representa na sua vida?; b) Quando a gente fala em amamentação, o que seria apoio para você?; c) Você recebeu apoio para amamentar seu filho?; d) Como você se sentiu estando no grupo do Projeto Amamenta Mamãe?; e) O grupo trouxe benefícios para você?; e f) O que você acha que poderia ser melhorado no grupo?.

Utilizou-se um gravador de voz digital e todas as entrevistas foram transcritas em sua literalidade, imediatamente após o término. Em seguida, realizou-se uma leitura inicial e sistematizaram-se anotaçôes ao longo do texto, com base no que foi observado no local. Essas informações incluíram as percepções não verbais identificadas, tais como características do ambiente de realização da entrevista; entonaçôes e gestos apresentados pelas mulheres; e expressóes faciais demonstradas nos momentos de silêncio.

Os dados foram analisados pela técnica da análise temática, à luz do referencial interpretativista ${ }^{14,15}$. Foram realizadas leituras flutuantes e releituras exaustivas para apropriação inicial do conteúdo das falas, seguida pela codificação e organização dos eixos temáticos extraídos pela leitura, apreensão dos núcleos de sentido e análise final dos textos. Todos os eixos temáticos foram extraídos das falas das entrevistadas.

Além da identificação e análise dos elementos categóricos, buscou-se também compreender as crenças, valores e subjetividades relacionadas ao processo de apoio vivenciado pelas mulheres durante a prática de amamentação, de modo a entender o objeto estudado com profundidade, por meio de um resgate das experiências vividas.

\section{Procedimentos éticos}

Para garantir o sigilo das informaçôes, as falas foram transcritas e arquivadas em meio digital, em documento protegido por senha, com acesso exclusivo aos pesquisadores do presente trabalho. A confidencialidade da identidade das usuárias foi garantida mediante a utilização de letras e números para codificação das entrevistadas. Este estudo foi aprovado pelo Comitê de Ética e Pesquisa do HULW, sob o número de CAAE 69841317.7.0000.5183. 


\section{Resultados}

Entre as mulheres entrevistadas, todas tiveram alguma experiência de amamentação exclusiva, variando de alguns dias até os seis meses preconizados pela OMS. A maioria delas residia com os companheiros e já havia vivenciado a experiência da maternidade previamente.

A análise das entrevistas possibilitou a identificação de cinco eixos temáticos: dificuldades relacionadas ao aleitamento materno; definição de apoio; identificação dos membros de suas redes sociais; contribuiçôes da inserção do grupo neste suporte; e principais limitaçóes apresentadas pela comunidade virtual. A tabela 1 apresenta a síntese dos eixos temáticos e subtemas identificados ao longo da análise.

Tabela 1. Síntese dos eixos temáticos e subtemas, Projeto Amamenta Mamãe, 2019.

\begin{tabular}{|c|c|}
\hline EIXO TEMÁTICO & SUBTEMAS \\
\hline \multirow{5}{*}{ Dificuldades relacionadas ao aleitamento } & Dificuldades físicas \\
\hline & Inseguranças \\
\hline & Impacto na identidade da mulher \\
\hline & Amamentar enquanto obrigação \\
\hline & Falta de apoio \\
\hline \multirow{3}{*}{ Definição de apoio } & Apoio emocional \\
\hline & Ajuda financeira \\
\hline & Apoio informativo \\
\hline \multirow{5}{*}{ Identificação da rede de apoio } & Família \\
\hline & Companheiro \\
\hline & Amigos \\
\hline & Profissionais de saúde \\
\hline & Projeto Amamenta Mamãe \\
\hline \multirow{6}{*}{ Processo de inserção do grupo na rede de apoio } & Apoio informativo \\
\hline & Confiabilidade de informações \\
\hline & Construção e ampliação de relações interpessoais \\
\hline & Fortalecimento da autonomia da mulher \\
\hline & $\begin{array}{l}\text { Compartilhamento de experiências contextualizadas } \\
\text { com a realidade }\end{array}$ \\
\hline & Promoção da autoconfiança materna \\
\hline \multirow[b]{2}{*}{ Limitações do grupo } & Virtualidade \\
\hline & $\begin{array}{l}\text { Fragilidades no acolhimento das mulheres que não } \\
\text { conseguiram amamentar }\end{array}$ \\
\hline
\end{tabular}

Fonte: Própria. 


\section{Dificuldades relacionadas ao aleitamento}

Os desafios vivenciados ao longo do processo de amamentação envolveram desde as dificuldades físicas, como fissuras e rachaduras nos seios, até os aspectos mais subjetivos, como sensaçôes de medo e insegurança em não conseguir amamentar. Esse sentimento foi evidenciado recorrentemente nos depoimentos, desvelando a complexidade e ambiguidade das sensaçôes que envolvem essa prática. "[Amamentação é] um momento de insegurança, muitas vezes" (M7). A noção de insegurança foi associada a outras dimensões negativas, como a frustração:

Eu acho que às vezes as pessoas fantasiam demais e quando chega na hora não é o que ela pensava. [...] o psicológico fica pensando mil e uma coisas: que você não vai dar conta, que não é tão legal isso tudo que tá acontecendo. (M8)

Outra dificuldade identificada foi relacionada ao impacto do processo de amamentação-parto-puerpério na identidade da mulher, ilustrando o aleitamento como uma fase contextualizada com vivências que decorrem dessa tríade. "[...] seu psicológico muitas vezes fica lá embaixo. Muito pra baixo, o estímulo da mulher, como mulher [libido] fica lá embaixo" (M8).

Observou-se que as dificuldades vivenciadas durante a amamentação fazem desse período um momento desafiador na vida da mulher. As usuárias demonstraram que isso contribuiu para que o aleitamento deixasse de ser uma fase prazerosa, gerando o sentimento de obrigação em amamentar.

[...] a amamentação pra mim não foi muito prazeroso, como muitas mães relatam. [...] pra mim a sensação foi um conflito porque eu me sentia na obrigação de dar. (M8)

Considerando a ambiguidade e os desafios que envolvem o processo de amamentação, muitas vezes a mulher não dispóe do suporte necessário à sua manutenção. Essa realidade emergiu nos relatos das entrevistadas. Uma delas, quando foi questionada se possuía apoio para amamentar, respondeu: "Não... é porque sempre foi só eu e Deus e meus meninos” (M9).

\section{Definição de apoio}

Ao serem questionadas acerca do conceito de apoio no âmbito do AME, a maioria das mulheres definiu como qualquer ajuda recebida, desde o auxílio com as atividades domésticas até a assistência financeira e psicológica. "[...] quando ela acorda de madrugada que eu tô com preguiça de levantar e colocar ela no peito, aí meu marido vai e pega ela, aí me dá um apoio enorme” (M4). “[...] apoio é também as condiçốes financeiras [...]” (M8). 
Outras participantes relataram o aspecto mais subjetivo do apoio, relacionando-o à amorosidade e à atenção: "Tem também a questão do acalento, de ajudar na ansiedade, conversar” (M10). Identificou-se também uma noção relacionada à orientação e incentivo para a manutenção do AME. "[...] tirar as dúvidas, porque querendo ou não a gente sempre tem alguma coisa a perguntar [...]” (M10). “[...] tem muito a questão do incentivo mesmo, né?!” (M11).

\section{Identificação da rede de apoio}

Nas falas das entrevistadas, a figura da família foi bastante expressiva, sendo fundamental nesse processo. Uma das mulheres demonstrou a necessidade de apoio advinda dos companheiros: "Meu marido é muito atencioso, [...] mas eu queria que ele me ajudasse mais. Revezasse comigo, sabe?! Principalmente à noite” (M11). Os amigos também foram identificados como integrantes dessa rede. "Eu tirava dúvida sempre com uma amiga minha que o filho dela também parou de mamar e tá na mesma idade que o meu" (M11).

No tocante ao papel dos profissionais de saúde nessa rede, a importância deles foi associada à realização de orientações adequadas. Porém, quando as mulheres foram questionadas acerca de como era a oferta desse apoio, percebeu-se que essas ações não contemplavam os desafios práticos do processo de aleitamento:

[...] nenhuma pediatra nunca me perguntou o formato do meu peito, nunca ninguém chegou pra me dizer: "olha, o bebê vai mamar assim, tal", ou então ensinar como a gente deve fazer em casa, mas não houve nada disso. (M5)

A maioria das entrevistadas identificou que o grupo virtual encontrava-se inserido em suas redes sociais de apoio ao AME. “[...] graças a Deus vocês do Projeto Amamenta Mamãe me ajudam pelo grupo. O grupo me dá apoio" (M1). "O apoio que eu tive foi de vocês, pelo Facebook” (M2). Uma das mulheres, quando foi questionada se possuía algum suporte, respondeu: "Não, só o pessoal do grupo, que desde que ela nasceu vem ajudando, tirando dúvidas” (M3), evidenciando que a única fonte de apoio era a comunidade virtual. A importância do grupo foi evidenciada em algumas falas, as quais demonstraram a necessidade de ampliação desses espaços a outras mulheres: "Era bom espalhar mais [o Projeto Amamenta Mamãe] para outras mães, porque não são todas que tiveram filhos no Hospital Universitário (HU). Isso ia ajudar mais as mães” (M5).

Ressalta-se o fato de a pesquisadora ser também uma das coordenadoras desse grupo virtual e o fato de que as mulheres tinham conhecimento desse vínculo, o que apresenta possíveis vieses. Portanto, para a superação dessa fragilidade, buscou-se conhecer as contribuiçôes advindas dessa comunidade virtual, aprofundando-se a análise crítica dessa estratégia. 


\section{Contribuições da inserção do grupo na rede social de apoio}

A análise das principais colaboraçóes do espaço virtual demonstrou que a realização de orientaçóes adequadas foi um dos papéis do grupo.

Teve também a questão do apoio, porque antes do grupo isso não existia. $\mathrm{Ou}$ minha mãe chegava e me dizia as crendices dela, ou vinha o vizinho e falava, aí eu fazia o que eu queria... não tinha ninguém pra compartilhar. (M4)

O gerenciamento do grupo por profissionais de saúde evocou a noção de credibilidade acerca das informaçóes compartilhadas, despertando maior confiança no espaço de apoio.

No grupo é confiável, porque eu sei que vocês trabalham nessa área e eu sei que vocês estão lá [no HU], esse é o ramo [amamentação] de vocês. É o trabalho de vocês, é o amor de vocês, é a profissão que vocês escolheram. Vocês estudaram pra isso. Então eu sentia mais confiança. (M10)

Analisando-se os aspectos metodológicos do Projeto Amamenta Mamãe, as mulheres destacaram a importância do enfoque participativo e dialógico:

Tem também as outras mães, os comentários, porque às vezes você tá passando pela mesma coisa e não sabe fazer e a outra mãe já sabe e já ensina a gente. (M1)

Têm mães que colocam que não estão conseguindo amamentar, dizendo que irão dar complemento... não que eu me frustre, né, mas eu penso que tá acontecendo a mesma coisa que aconteceu comigo. Não acredito que seja uma frustração, mas assim: "Nossa, ela tá passando pela mesma coisa que eu tô passando”. Isso é ajudar! (M5)

Verificou-se que a estratégia também foi importante para preparar as mulheres para os possíveis desafios a serem vivenciados na fase de AME. Algumas usuárias relataram que a busca pelo grupo ocorreu antes mesmo da dificuldade se instalar:

[...] [eu procuro o grupo] curiosa, das pergunta dos povo e o que eles vai dizer. Porque se acontecer com meu filho eu já sei como faço. Mesmo sem a dificuldade eu procuro o grupo. Teve uma que aconteceu um negócio, um problema, aí eu já fiquei de olho. (M6)

Destacou-se que o cenário virtual também era uma companhia para as mulheres, haja vista que, durante o aleitamento materno, muitas delas ficavam em casa enquanto todos os familiares saíam para realizar suas atividades rotineiras. "O grupo representou uma alegria na minha vida, porque eu era muito calada, não tinha com quem conversar. Minha família não é daqui [...]. E o grupo a gente forma amigo, fica conversando” (M2). Portanto, notou-se que essa estratégia consistia em um meio de ampliação de relaçóes e 
aproximação de pessoas que possuíam vivências similares. "Eu pegava o nome de alguém que eu via que se comunicava mais nos comentários, aí eu falava com elas no privado, essas coisas. Minha lista de amigos aumentou bastante [risos]" (M4).

\section{Limitações do Projeto Amamenta Mamãe}

Além das potencialidades evidenciadas, foram identificados alguns desafios que necessitam ser observados pela comunidade virtual. Um dos aspectos ressaltados foi a própria virtualidade, na qual algumas mulheres relataram a importância de que houvesse encontros presenciais para complementar o processo de apoio e promover maior aproximação entre as participantes.

Acho que deve melhorar porque deve ter reunião presencial, pra escutar as coisa [...]. Devia ter pelo menos uma vez no mês pelo menos um momento presencial, todo mundo junto, pra nós conhecer os povo, porque fica chato, a gente fala e não sabe com quem, né?! (M6)

Em contrapartida, quando algumas das entrevistadas foram questionadas se o fato de o grupo ser virtual representava um obstáculo, ressaltaram os recursos tecnológicos como aliados:

[...] hoje em dia a tecnologia é feita pra isso, né? Pra, independente de distância, as pessoas estão sempre se comunicando [...]. Se você marcasse uma reunião uma vez por mês, nem todas iriam. (M9)

Aprofundando o entendimento dos desafios identificados, verificou-se que a principal limitação do grupo foi evidenciada pelas usuárias que não conseguiram amamentar até o sexto mês de vida da criança. Quando essas mulheres foram questionadas sobre a sensação de estar no grupo sem amamentar, percebeu-se que houve limitações no acolhimento dessas vivências: “[...] eu me sentia a pior mãe do mundo [...]" (M5). "Eu me sinto excluída do grupo [...]. Acaba que as postagens, quando vocês me marcam que mostram os benefícios, eu vejo o que ele tá perdendo [...]” (M11).

\section{Discussão}

O processo de aleitamento materno é permeado por diversas dificuldades, envolvendo aspectos físicos, psicológicos e emocionais. Muitas vezes, esses desafios despertam a sensação de insegurança na vida da mulher, contribuindo de forma significativa para a descontinuidade da amamentação16. Necessita-se fortalecer o apoio ao aleitamento materno desde o período de internação da mulher nas maternidades. $\mathrm{O}$ apoio oportuno nessa etapa demonstra uma associação positiva com as maiores prevalências de AME17. 
A necessidade de apoio emergiu na fala das entrevistadas, conforme observado nos resultados da presente análise. Apesar disso, as açôes ofertadas pelos profissionais de saúde têm sido predominantemente teóricas e informativas, deixando de preparar a mulher para as possíveis dificuldades encontradas e reforçando a frustração vivenciada durante o aleitamento ${ }^{18,19}$ PubMed, Medline, Lilacs, SciELO, Web of Science and Cumulative Index to Nursing and Allied Health Literature (Cinahl.

Uma das falas demonstrou o impacto dos processos de amamentação, parto e puerpério na identidade da usuária. Trata-se de um reflexo de como a maternidade é concebida na contemporaneidade, na qual a amamentação é vista como um processo natural, conferindo à mulher a sua vocação em ser mãe e produzindo-se uma expectativa de habilidade nata para o desempenho da amamentação ${ }^{20}$. As estratégias de apoio devem conceber a mulher para além da figura de mãe, entendendo-a como sujeito inserido em um contexto social, histórico e cultural. Essas açôes devem compreender o aleitamento como uma fase de ressignificação de sua feminilidade ${ }^{21}$. O grupo abordou as discussóes de maneira contextualizada com as diferentes vivências, porém, não aprofundou esse debate, demonstrando uma das fragilidades da estratégia.

Ao serem questionadas acerca do significado de apoio, as mulheres relataram as diferentes dimensóes que permeiam esse conceito, envolvendo o suporte psicossocial, bem como o aspecto informativo. No contexto das vertentes de promoção da alimentação saudável, a definição de apoio engloba todas as açóes necessárias para facilitar a adoção dessas práticas, incluindo desde a garantia da informação e criação de políticas públicas até $\mathrm{o}$ aspecto motivacional ${ }^{22}$.

As ações de educação em saúde tradicionais, com caráter puramente informativo e prescritivo, são insuficientes para contemplar todos os desafios relacionados à amamentação, bem como para oferecer o suporte necessário à superação desses impasses ${ }^{18}$. A hegemonia dessas práticas reforça os paradigmas referentes ao aleitamento enquanto realidade inerente à vida da mulher e seu insucesso só aumenta o sentimento de frustração vivenciado por esse público. Deve-se fomentar a construção de relações dialógicas entre profissionais e usuárias, superando as diferenças de gênero e poder em relação à figura materna. Almeja-se pelo rompimento com a abordagem histórica que vincula a mulher à figura de mãe, com a função exclusiva de nutrir o filho ${ }^{23}$.

Os profissionais da saúde foram apontados como membros importantes da rede social de apoio da mulher, principalmente no que diz respeito à dimensão informativa. As entrevistas demonstraram que o gerenciamento do grupo virtual por trabalhadores do hospital em que as usuárias realizaram o parto garantiu maior confiabilidade das participantes em relação às informaçóes compartilhadas virtualmente ${ }^{10}$. As mulheres que vivenciam a fase de aleitamento têm maior necessidade conhecimento procedente de profissionais de saúde, com base em alguns recursos, dentre eles os websites de amamentação ${ }^{24}$. Dessa forma, a construção de vínculos entre trabalhadores e usuários durante as abordagens de apoio ao AME é fundamental no processo de apoio ${ }^{25}$. 
A garantia de informaçóes consideradas seguras, apesar de ter sido evidenciada como uma das principais contribuições do grupo, é apenas um dos aspectos que deve ser levado em consideração no momento da realização das abordagens, haja vista que contribui para fortalecer os conhecimentos relacionados ao AME auxiliando na sua manutenção $0^{26}$, porém, não se limita a isso.

Apesar das potencialidades dos profissionais de saúde para o suporte adequado, estudos sinalizaram que muitas de suas açóes são caracterizadas pela transmissão de informaçóes teóricas, desconsiderando os aspectos práticos do aleitamento e todas as dificuldades vivenciadas nesse processo ${ }^{18}$. Essa evidência também emergiu na fala das entrevistadas. A principal limitação dessas atividades é a descontinuidade das ações, tendo em vista que a maioria delas é caracterizada por apenas uma prática individual ou em grupo ${ }^{27}$. Faz-se necessário fortalecer ações de apoio que valorizem a problematização e o diálogo, inserindo ativamente os sujeitos envolvidos no processo ${ }^{28}$.

As ações virtuais com abordagem participativa têm sido destacadas como importantes cenários de apoio ao AME, levando-se em consideração que a busca por informaçôes em saúde por meio desses espaços tem apresentado crescimento relevante, principalmente entre mulheres após a alta hospitalar ${ }^{11,29}$. O suporte on-line é enxergado como uma estratégia promissora para a manutenção do $\mathrm{AME}$ até os seis meses de vida da criança, minimizando o desmame precoce e a utilização de fórmulas lácteas ${ }^{30}$.

Entendendo-se que as açôes de apoio ao AME encontram-se integradas no âmbito de um processo educativo, destaca-se a necessidade de que essas práticas extrapolem a perspectiva puramente informativa, resgatando a autonomia dos indivíduos, possibilitando que estes sejam partícipes do processo, e não apenas receptores de informação. Necessita-se reorientar as estratégias, valorizando-se as experiências pessoais, além de se compreender holisticamente a realidade dos diferentes grupos sociais que integram a vida da mulher ${ }^{31}$.

A utilização da CBPR on-line no cenário do Projeto Amamenta Mamãe contribuiu para que as publicaçôes fossem realizadas a partir das demandas apresentadas pelas mulheres, garantindo uma perspectiva contextualizada às intervençóes realizadas. A utilização dessa metodologia contribuiu para que esse espaço não se tornasse apenas uma fonte unidirecional de informação, fortalecendo o diálogo e a participação das mulheres no grupo. Isso colaborou na implementação de uma comunidade virtual em que a troca de saberes, a construção de relações e a identificação mútua de experiências e aprendizados foram uma das principais potencialidades da intervenção, conforme observado entre as falas. A utilização de estratégias participativas no apoio ao AME é fundamental, uma vez que possibilita a construção de conhecimentos pautada no aprendizado crítico acerca da realidade e dos problemas vivenciados ${ }^{25}$.

A CBPR já foi utilizada em diferentes intervençôes ${ }^{32}$, porém, estudos que trabalhem a CBPR on-line ainda são escassos. Trata-se de importante estratégia colaborativa de ensino-aprendizagem, abordando o tema que é relevante para a comunidade - no caso da presente pesquisa, uma comunidade virtual -, representando um instrumento de articulação entre o conhecimento científico e a prática social ${ }^{12,13}$ 
Por meio do fortalecimento dessa estratégia no Projeto Amamenta Mamãe, uma das principais contribuições da inserção do grupo na rede social de apoio das mulheres foi a construção e ampliação das relaçôes interpessoais. A análise das falas demonstrou a importância da integração entre sujeitos com experiências similares, na medida em que fortalece o compartilhamento de vivências, desafios, anseios e inquietudes. Percebeu-se que um dos motivos pelos quais as participantes buscaram o espaço foi o anseio por conhecimento sobre essas experiências. O diálogo foi um dos aspectos fundamentais, considerando a característica educativa do projeto, favorecendo que os partícipes do processo extrapolassem o nível ingênuo das inquietaçóes para um conhecimento crítico da realidade ${ }^{33}$.

A troca de experiências garantiu um enfoque prático ao apoio ofertado pelo grupo virtual. Antes mesmo das dificuldades se instalarem, esse compartilhamento possibilitou que as mulheres enxergassem os desafios a serem enfrentados, identificando as possíveis estratégias para superá-las. Vislumbra-se o despertar da curiosidade e interesse das usuárias pela temática de AME, demonstrando uma dimensão fundamental da prática educativa, na medida em que articula os conhecimentos com a realidade dos sujeitos ${ }^{33}$.

A potencialidade dessa estratégia virtual no cenário brasileiro foi sistematizada em um estudo inovador realizado por Silva e colaboradores, cujo cenário de intervenção foi o grupo virtual Projeto Amamenta Mamãe. Os pesquisadores realizaram um ensaio clínico randomizado e identificaram que essa prática on-line impactou positivamente na frequência e na duração do aleitamento materno exclusivo ${ }^{34}$.

O compartilhamento de vivências com o aleitamento nos grupos e fóruns virtuais proporciona na mulher não apenas o sentimento de maior segurança frente às dificuldades encontradas, mas também um momento de identificação e compreensão desse processo ${ }^{35}$. Possibilita-se fortalecer a autoconfiança materna acerca de sua capacidade em amamentar, aspecto essencial no apoio ao aleitamento ${ }^{36}$. Essa integração entre as usuárias que vivenciam esse processo contribui na ampliação da sua rede social de apoio, favorecendo a manutenção da amamentação ${ }^{37}$.

As análises deste estudo possibilitaram compreender a importância dos membros da rede social de apoio dessas mulheres, principalmente os amigos, familiares e companheiro(a)s, corroborando com os resultados de diferentes autores ${ }^{37}$. Percepçóes desfavoráveis à amamentação por parte dessas pessoas influenciam negativamente a decisão em amamentar. Necessita-se fortalecer as práticas de educação em saúde, integrando não apenas as mulheres no âmbito dessas estratégias, mas também todos esses indivíduos. Apesar do desafio, a inserção das nutrizes e seus familiares no contexto das práticas educativas contribuem para fortalecer o apoio ao AME, despertando sentimentos de alegria, satisfação e gratidão aos diferentes atores envolvidos nessas açốes ${ }^{28}$.

Durante essa fase de avaliação, as ações do Projeto Amamenta Mamãe foram destinadas apenas às mulheres após a alta hospitalar. Diante disso, as análises contribuirão na posterior ampliação do público-alvo da comunidade virtual, inserindo os diferentes integrantes da rede social de apoio dessas usuárias. 
A principal limitação apresentada pelo grupo foi relacionada à fragilidade no acolhimento dos moderadores quanto às mulheres que não conseguiram realizar o AME até o sexto mês de vida da criança. Apesar de a importância dessa prática ser demonstrada e de se elencar todas as estratégias possíveis para mantê-la, verifica-se a necessidade de postagens acolhedoras, que integrem as mulheres que estejam nessas situaçóes, no intuito de auxiliá-las conforme as suas experiências pessoais. Em análise realizada em fóruns on-line, identificou-se que, entre as usuárias que optavam por introduzir fórmulas, algumas se sentiam pressionadas pelos profissionais a manterem o aleitamento, mesmo tendo feito opção contrária, relatando ainda que deixaram de receber o apoio necessário após essa decisão ${ }^{35}$.

\section{Conclusão}

O Projeto Amamenta Mamãe tem se constituído um importante espaço de apoio ao AME, por meio do estímulo ao diálogo e à interação. A troca de experiências e subjetividades existentes neste espaço contribuiu para a melhoria dos conhecimentos e promoção da autoconfiança das mulheres em relação à capacidade de amamentar. O diálogo entre todos os participantes - mulheres e moderadores - foi o ponto mais importante dessa prática, uma vez que buscou promover o empoderamento dessas pessoas neste período das suas vidas.

A inserção dos pressupostos da CBPR como metodologia de intervenção do grupo foi importante para inserir um enfoque participativo neste cenário, trazendo contribuiçôes relevantes à promoção da autonomia das usuárias do grupo. Levando-se em consideração que a $\mathrm{CBPR}$ propóe que a construção do objeto de pesquisa se dê por todos os sujeitos envolvidos, estes achados têm subsidiado reformulaçóes de algumas das limitaçóes do grupo identificadas pelas mulheres e pela literatura, entre elas, a não inserção dos demais membros da rede social das usuárias, bem como a falta de postagens acolhedoras em relação às que não conseguem/desejam manter o AME.

As principais contribuiçôes da inserção do projeto na rede social de apoio das mulheres se deram por meio da realização de orientações adequadas, bem como do fortalecimento de relaçóes e da troca de experiências. O gerenciamento desse espaço por profissionais de saúde foi fundamental para a credibilidade das participantes em relação ao apoio ofertado e às informaçóes e vivências compartilhadas. Destaca-se a necessidade de inserir os espaços virtuais nos processos de trabalho das instituições envolvidas com a promoção do $\mathrm{AME}$, incrementando as ferramentas dessa natureza.

Diante da escassez de pesquisas avaliativas sobre as estratégias virtuais de apoio ao aleitamento materno, salienta-se a necessidade de se promover estudos em outros cenários on-line para além dos gerenciados por profissionais de saúde. 


\section{Contribuições dos autores}

Todos os autores participaram ativamente de todas as etapas de elaboração do manuscrito.

\section{Agradecimentos}

A todos os integrantes da equipe do Projeto Amamenta Mamãe, pelo apoio para a concretização deste trabalho. Ao Hospital Universitário Lauro Wanderley, pelo apoio para o desenvolvimento desta pesquisa.

\section{Direitos autorais}

Este artigo está licenciado sob a Licença Internacional Creative Commons 4.0, tipo BY (https://creativecommons.org/licenses/by/4.0/deed.pt_BR)..

\section{(cc) BY}

\section{Referências}

1. Liu L, Oza S, Hogan D, Perin J, Rudan I, Lawn JE, et al. Global, regional, and national causes of child mortality in 2000-13, with projections to inform post-2015 priorities: an updated systematic analysis. Lancet. 2015; 385(9966):430-40. doi: http://dx.doi.org/10.1016/S0140-6736(14)61698-6.

2. Victora CG, Bahl R, Barros AJD, França GVA, Horton S, Krasevec J, et al. Breastfeeding 1 Breastfeeding in the 21st century : epidemiology, mechanisms, and lifelong eff ect. Lancet. 2016; 387(10017):475-90. doi: http://dx.doi.org/10.1016/ S0140-6736(15)01024-7.

3. Géa-Horta T, Silva RDCR, Fiaccone RL, Barreto ML, Velásquez-Meléndez G. Factors associated with nutritional outcomes in the mother-child dyad: a population-based cross-sectional study. Public Health Nutr. 2016; 19(15):2725-33.

4. De Mola CL, Horta BL, Gonçalves H, Quevedo LDA, Pinheiro R, Gigante DP, et al. Breastfeeding and mental health in adulthood: a birth cohort study in Brazil. J Affect Disord. 2016; 202:115-9. doi: http://dx.doi.org/10.1016/j.jad.2016.05.055.

5. World and Health Organization. Indicators for assessing infant and young child feeding practices: part 2: measurement [Internet]. Geneva: WHO; 2010 [citado 2 Set 2019]. Disponível em: https://apps.who. int/iris/bitstream/handle/10665/44306/9789241599290_eng. pdf;jsessionid=31CAF915677F4728ED536A83FCC4C705 ? sequence $=1$

6. Venancio SI, Escuder MML, Giugliani ERJ. A prática do aleitamento materno nas capitais brasileiras e Distrito Federal: situação atual e avanços. J Pediatr. 2016; 86(4):317-24.

7. Centers for Disease Control and Prevention. Breastfeeding report card [Internet]. Atlanta: CDC; 2014 [citado 2 Set 2019]. Disponível em: https://www.cdc.gov/ breastfeeding/pdf/2014breastfeedingreportcard.pdf 
8. Rollins NC, Bhandari N, Hajeebhoy N, Horton S, Lutter CK, Martines JC, et al. Why invest, and what it will take to improve breastfeeding practices? Lancet. 2016; 387(10017):491-504. doi: http://dx.doi.org/10.1016/S0140-6736(15)01044-2.

9. Haaron S, Das JK, Salam RA, Aamer Imdad, Bhuta Z. Breastfeeding promotion interventions and breastfeeding practices. BMC Public Health. 2013; 13 Suppl 3:1-18.

10. Bridges $\mathrm{N}$. The faces of breastfeeding support: experiences of mothers seeking breastfeeding support online.itle. Breastfeed Rev J [Internet]. 2016 [citado 2 Set 2019]; 24(1):11-20. Disponível em: https://www.ncbi.nlm.nih.gov/ pubmed/27188074

11. Harari N, Rosenthal MS, Bozzi V, Goeschel L, Jayewickreme T, Onyebeke C, et al. Feasibility and acceptability of a text message intervention used as an adjunct tool by WIC breastfeeding peer counsellors: the LATCH pilot. Matern Child Nutr. 2018; 14(1):1-11.

12. Israel BA, Coombe CM, Cheezum RR, Schulz AJ, McGranaghan RJ, Lichtenstein $\mathrm{R}$, et al. Community-based participatory research: a capacity-building approach for policy advocacy aimed at eliminating health disparities. Am J Public Health. 2010; 100(11):2094-102.

13. Warllestein N, Duran B. Community-based participatory research contributions to intervention research: the intersection of science and practice to improve health equity. Am J Public Health. 2010; 100 Suppl 1:40-7.

14. Minayo MCS. O desafio do conhecimento: pesquisa qualitativa em saúde. São Paulo: Hucitec; 2010.

15. Machado RCM, Baião MR, Líbera B Della, Saunders C, Santos MMADS. The symbolic dimension of prenatal nutrition care in diabetes Mellitus. Rev Nutr. 2017; 30(6):703-11.

16. Rocci E, Fernandes RAQ. Dificuldades no aleitamento materno e a influência no desmame precoce. Rev Bras Enferm. 2014; 67(1):22-7.

17. Passanha A, Benício MHD, Venâncio SI, Reis MCG. Influência do apoio ao aleitamento materno oferecido pelas maternidades. Rev Saude Publica. 2015; 49:1-10.

18. Almeida JM, Luz SDAB, Ued FDV. Apoio ao aleitamento materno pelos profissionais da saúde: uma revisão de literatura. Rev Paul Pediatr. 2015; 33(3):356-63. doi: http:// dx.doi.org/10.1016/j.rpped.2014.10.002.

19. Nyawade SA, Middlestadt SE, Peng CYJ. Beliefs about supporting mothers to exclusively breastfeed for 6 months: an elicitation study of health professionals working in maternal-child health clinics in Nairobi, Kenya. J Hum Lact. 2016; 32(3):551-8.

20. Giordani RCF, Piccoli D, Bezerra I, Almeida CCB. Maternidade e amamentação: identidade, corpo e gênero. Cienc Saude Colet. 2018; 23(8):2731-9.

21. Marshall J. Motherhood, breastfeeding and identity. Pract Midwife. 2011; 14(2):16-8.

22. Hawkes C. Promoting healthy diets through nutrition education and changes in the food environment: an international review of actions and their effectiveness [Internet]. Roma: FAO; 2013 [citado 2 Set 2019]. Disponível em: http://www.fao.org/3/i3235e/i3235e.pdf

23. Cadoná E, Strey MN. A produção da maternidade nos discursos de incentivo à amamentação. Estud Fem. 2014; 22(2):477-99.

24. Ouyang YQ, Su M, Redding SR. A survey on difficulties and desires of breastfeeding women in Wuhan, China. Midwifery. 2016; 37:19-24. doi: http://dx.doi. org/10.1016/j.midw.2016.03.014. 
25. Linhares F, Pontes $\mathrm{C}$, Osorio $\mathrm{M}$. Breastfeeding promotion and support strategies based on Paulo Freire's epistemological categories. Rev Nutr. 2013; 26(2):125-34.

26. Sabin A, Mansur F, Adil S. Exclusive breastfeeding practices in working women of Pakistan : a cross sectional study. J Med Sci. 2019; 39(4):1148-55.

27. Wong KL, Tarrant M, Yuet K, Lok W. Group versus individual professional antenatal breastfeeding education for extending breastfeeding duration and exclusivity : a systematic review. J Hum Lact. 2015; 31(3):354-66.

28. Queiroz P, Pontes C. Significados das açôes educativas de enfermagem centradas na amamentação na perspectiva das nutrizes e familiares. Rev Enferm Ref. 2012; Série III (8):95-103.

29. Bartholomew MK, Schoppe-Sullivan SJ, Glassman M, Kamp Dush CM, Sullivan JM. New parents' facebook use at the transition to parenthood. Fam Relat. 2012; 61(3):455-69.

30. Newby R, Brodribb W, Ware RS, Davies PSW. Internet use by first-time mothers for infant feeding support. J Hum Lact. 2015; 31(3):416-24.

31. Freire P. Pedagogia da autonomia: saberes necessários à prática educativa. 43a ed. Rio de Janeiro: Paz \& Terra; 2011.

32. Kumar J, Kidd T, Li Y, Lindshield E, Muturi N, Adhikari K. Using the communitybased participatory research (CBPR) approach in childhood obesity prevention. Int $\mathrm{J}$ Child Health Nutr. 2014; 3(4):170-8.

33. Freire P. Pedagogia do oprimido. 67a ed. Rio de Janeiro: Paz \& Terra; 2013.

34. Cavalcanti DS, Cabral CS, Vianna RPT, Osório MM. Online participatory intervention to promote and support exclusive breastfeeding: randomized clinical trial. Matern Child Nutr. 2019; 15(3):1-12.

35. Wennberg AL, Jonsson S, Janke JZ, Hörnsten Å. Online perceptions of mothers about breastfeeding and introducing formula : qualitative study. JMIR Public Health Surveill. 2017; 3(4):1-7.

36. Jama NA, Wilford A, Masango Z, Haskins L, Coutsoudis A, Spies L, et al. Enablers and barriers to success among mothers planning to exclusively breastfeed for six months: a qualitative prospective cohort study in KwaZulu-Natal, South Africa. Int Breastfeed J. 2017; 12(43):1-13.

37. DeVane-Johnson S, Woods-Giscombé C, Thoyre S, Fogel C, Williams R. Integrative literature review of factors related to breastfeeding in african american women: evidence for a potential paradigm shift. J Hum Lact. 2017; 33(2):435-47. 
Despite the health benefits of exclusive breastfeeding to moms and their children, its early interruption is still quite common. After hospital discharge is the period when women face the most challenges, being important to strengthen breastfeeding support actions. This study aimed at unveiling the contributions of including a virtual community in a social support network to exclusive breastfeeding after hospital discharge. This qualitative study was conducted in a private Facebook group managed by health professionals using a Community-Based Participatory Research as methodological reference. The group was used to foster dialog and interaction among women based on experiences contextualized in the real world, being possible to build new interpersonal relationships and expand their support networks.

Keywords: Exclusive breastfeeding. Breastfeeding support. Social media. Social support.

Community-based participatory research.

A pesar de los beneficios de la lactancia materna exclusiva para la salud materno-infantil, su interrupción precoz todavía es muy frecuente. El período después de recibir el alta en el hospital es el momento en el que la mujer se depara con la mayoría de las dificultades, siendo importante fortalecer las acciones de apoyo a la lactancia. Este trabajo tuvo el objetivo de desvelar las contribuciones de la inserción de una comunidad virtual en la red social de apoyo a la lactancia materna exclusiva de mujeres después de recibir el alta del hospital. Se trata de un estudio cualitativo, realizado en un grupo privado de la red social facebook, administrado por profesionales de la salud, utilizando como referencial metodológico la Encuesta Participativa Basada en la Comunidad. El grupo fue un instrumento de promoción de diálogo e interacción entre mujeres a partir de experiencias contextualizadas con la realidad, propiciando la construcción de nuevas relaciones interpersonales, ampliando sus redes sociales de apoyo.

Palabras clave: Lactancia materna exclusiva. Apoyo a la lactancia materna. Redes sociales. Apoyo social. Encuesta participativa basada en la comunidad. 